\title{
MARKETING EM LOCALIDADES HISTÓRICAS E TURISMO CULTURAL
}

\author{
Mário Jorge Pires ${ }^{1}$ \\ Mylene Cyrino Basso ${ }^{2}$
}

\begin{abstract}
RESUMO: Inúmeras são as possibilidades de dinamizar um museu ou localidade histórica, bastando, para tanto, inserir sua finalidade cultural e pedagógica ao conceito de eficiência, que abrange bens e serviços, dentre os quais o turismo cultural. Este artigo traça algumas diretrizes de ação face à penúria atual de recursos.
\end{abstract}

PALAVRAS-CIIAVE: Marketing cultural; turismo cultural; oferta turistica; recursos turisticos; captação de recursos.

ABSTRACT: There are many possibilities to appley dynamics to a museum or a historical place.In order that, it's enough to insert its cultural and pedagogical functions in the excellence concept, which includes goods and services, the cultural tourism among that. This article describes some directive actions in face of the actual lack of resources.

KEY WORDS: Cultural marketing; cultural tourism; tourist offer; resources; resources attainment.

\section{INTRODUÇÃO}

\section{A pouca bibliografia}

o empresário brasileiro como pouco afeito às iniciativas de patrocínio da cultura, o que em parte pode representar a realidade de alguns setores não acostumados ou mesmo resistentes a novas concepções de marketing institucional. Hoje, porém, não apenas as empresas multinacionais, mas um

1 Doutor e Professor do Curso de Turismo da Escola de Comunicações e Artes da Universidade de São Paulo.

End. para corresp.: Rua Nicolau Piratininga, 72 - Penha - 03643-000 - São Paulo - SP - Brasil.

2 Bacharel em Propaganda e Publicidade pela Escola de Comunicaçõese Artes da Universidade de São Paulo. Analista de Marketing da Anhembi Turismo e Eventos da Cidade de São Paulo S/A. End. para corresp.: Rua Nicolau Piratininga, 72 - Penha - 03643-000 - São Paulo - SP - Brasil. 
número cada vez maior de empresários e executivos ligados à prestação de serviços, ou mesmo indústrias com capital brasileiro, abrem-se para estes conceitos que fazem da relação empresa-cultura uma parceria salutar, cujos benefícios vão muito além das concepções arcaicas do puro mecenato.Pertencentes à esfera da administração pública, os museus c localidades históricas, em sua maioria, padecem de uma crônica falta de verbas. Esta poderia ser amenizada através de captação de recursos da iniciativa privada, não fossem o preconceito de diretores e demais responsáveis e/ou as amarras de legislações já há muito obsoletas ante a realidade e responsabilidade do governo, no que concerne à sua participação em todos os setores da sociedade.

Com isso, o que se observa é uma verdadeira subutilização e esvaziamento destes locais, que de outra forma poderiam representar uma importante opção dentro do turismo cultural, ou mesmo cumprir suas funções educativas de forma eficiente, independentemente até de um fluxo organizado de turistas.

Captar recursos para estas localidades não é apenas uma questão política, mas requer uma atualização no instrumental administrativo nem sempre presente nos organismos públicos (e às vezes privados). Obter verbas de empresas exige, por isso, que ambos os lados tenham flexibilidade na tomada de posições e empenho constante em digerir novas abordagens e tendências. Não é por outro motivo que museus ou casas de cultura pertencentes a fundações, normalmente costumam ter melhor funcionamento do que aqueles sob jurisdição de órgãos públicos, conseguindo, com maior freqüiência, os recursos de que necessitam.

\section{AÇÃO ANTE A PRECARIEDADE DE VERBAS}

A realidade que tomou corpo nos últimos anos mostrou o colapso do Estado forte, centralizador e, ao mesmo tempo, autoritário. Questiona-se, não sem motivo, se este modelo deva fazer parte das novas concepções dos anos 90 , principalmente em países subdesenvolvidos repletos de problemas tão sérios, como os de saúde e educação. Gastar muitos milhares de dólares para restaurar o Teatro Municipal de São Paulo pode parecer importante a determinados gnupos, porém uma administração pública eficiente levará em conta muito mais a precariedade de saneamento básico, educação, saúde $\mathrm{e}$ abastecimento. Isso não quer dizer que o Estado não deva ter nenhuma participação e responsabilidade no que concerne à cultura de um modo geral, mas que seus esforços devem se concentrar muito mais em novas formas de desamarrar os entraves burocráticos que impedem a participação da iniciativa privada nesta área.
O desinteresse do empresário brasileiro $\mathrm{cm}$ apoiar a cultura normalmente não é bem entendido. Como demonstrou MUYLAERT (1993), a generosidade do brasileiro é imensa, mas via de regra castrada pelo próprio governo, que cria empecilhos de toda ordem para as doações. Por isso, ao contrário dos Estados Unidos, o Brasil não é um país de doadores. Criou-se o mito de que o empresário não está interessado em apoiar a cultura. O que ocorre é que alguns realmente não estão, como é fato, também, que não poucos agentes culturais sequer sabem conversar com empresários. Muitos apresentam planos pouco consistentes, baseados às vezes no único argumento de que a iniciativa privada tem um compromisso moral de financiar os artistas em suas realizações. Planilhas de custos malfeitas, desorganizações de todo gênero e, principalmente, ausência do modo como o apoio ao evento pode representar a contrapartida em termos de algumas vantagens para a cmpresa patrocinadora, são itens desinteressantes a muitos agentes culturais ${ }^{3}$. O resultado, assim, não poderia ser diferente: diminuta captação de recursos.

O problema ainda é agravado pelo preconceito de certos diretores que, ideologicamente, ainda consideram uma ameaça a presença da iniciativa privada em "seus" museus. Quando consentem, aceitam, no máximo, a presença de mantenedores que, anonimamente, abririam seus cofres para arcar às custas de muitos milhares de dólares com os déficits anuais.

Obedecer o princípio fundamental de parceria é fundamental, onde tanto os agentes culturais como as empresas saem ganhando. Apoios a realizações artísticas fazem parte de estratégias de marketing de empresas, assim como os gastos com a propaganda em anúncios diretos na mídia. Como fruto estão o investimento na imagem institucional da empresa e o incremento das atividades culturais (PHILLIPS, 1992).

Como iniciar, pois, um programa de captação de recursos? Ao contrário do que normalmente se pensa, não é necessariamente obrigatória a instalação de uma house. Antes de mais nada, o que se necessita é de alguns profissionais dinâmicos. Na seleção deverão ser levados em conta itens que podem representar a diferença entre a execução de atividades puramente convencionais - incluindo-se a continuidade de programações sobejamente desgastadas e, por isso, pouco ou nada divulgadas pela imprensa - ou a dinamização que, fatalmente, exigirá outra postura. Uma contratação exigirá dos candidatos as seguintes características:

a) facilidade de lidar com a imprensa: foi-se o tempo em que o envio de um press-release bastava para a imprensa noticiar. Hoje, o trabalho de

3 Esta realidade jä fora descrita de forma bastante precisa por MUYLAERT (1993) 
assessoria de imprensa exige dedicação integral c capacidade de dialogar com os responsáveis pela publicação. Pode-se afirmar que, $\mathrm{cm}$ alguns casos, não há patrocínio sem mídia c é fácil entender o ponto de vista do empresário: ele gastará se a imprensa der o apoio noticiando;

b) saber conversar com o empresário: isso significa que, objetivamente, o empresário enxergará a proposta como um produto que, cmbora cultural, tratar-se-á de algo bom ou não, conveniente para a empresa ou descartável. Projetos "lindos" só cxistem nas mentes dos agentes culturais, não nas dos empresários;

c) saber lidar com certos aspectos da propaganda: negociar tabelas de preços pode ser atividade de um vendedor treinado c, por isso, traquejado no ato de conquistar maiores descontos junto aos veículos de comunicação. Mas saber os canais corretos para cada tipo de evento cxige muito mais do que talento de vendedor.

\section{CONCEITO DE "EXCELÊNCIA" APLICADO A LOCALIDADES HISTÓRICAS}

Que museus c localidades históricas possam representar uma importante opção no quadro de operação de turismo c lazer culturais não constitui novidade. Os problemas comę̧am a despontar exatamente no momento cm que, na verificação dos roteiros, certos muscus não têm bebedouros c os banheiros funcionam precariamente.

Interessar o cidadão comum é o grande desafio dos muscus c localidades históricas. A idéia não é nova c muitos exemplos podem ser citados, como o do Muscu Germânico de Nuremberg, que introduziu, há muito tempo atrás, uma espécie de vitrine para a rua. Nela, eram estrategicamente colocados objetos que chamassem a atenção do transcunte que, curioso, acabava entrando para conhecer o museu.(SHAEFFER, 1963)

Um sem-número de artigos de especialistas clamam pelo conceito de "excelência" nos bens e serviços. Mais do que um modismo, as estratégias que estão se delineando desembocam inelutavelmente no reforço da imagem da empresa, através de produtos que satisfaçam plenamente as expectativas do consumidor. O mercado já processa um peneiramento dos melhores, não obstante as resistências de alguns setores oligopolizados.

Qualidade e eficiência: encantar o consumidor, fazê-lo fiel a uma marca ou griffe; são estes os desafios empresariais. A educação c a cultura não ficarão alheias a estas transformações. Localidades históricas não visitadas e museus autofágicos serão cada vez mais questionados c pressões automaticamente ocorrerão no sentido de que maximizem o cumprimento de suas funções culturais.
A aplicação do conceito de "excelência" cm museus e localidades históricas abrange uma administração que leve em conta a cxistência de monitores bem-treinados, biblioteca atualizada e funcionando com eficiência, banheiros c bebedouros higiênicos, estacionamento c dependências com segurança, livraria e loja de souvenirs bem equipadas, lanchonete, cafeteria ou restaurante integrados à atmosfera do lugar, entre outros itens. Utopia? Não. Todo diretor de museu sabe que isso só se consegue com dinheiro. Com verbas específicas que a cada ano minguam ainda mais.

Se a legislação de muitos museus c casas históricas não permitc ou emperra a parceria com a iniciativa privada, talvezo enfoqueda adminstração não deva ser voltada num primeiro momento ao marketing, mas a formas e procedimentos de tornar estatutos e regimentos mais elásticos face à realidade da penúria.

\section{EVENTOS NAS LOCALIDADES HISTÓRICAS}

Longe de querer esgotar as possibilidades de realização de eventos em museus e bens históricos, cstãoabaixo algumas das inúmeras variações que, certamente, a criatividade ampliará até limites hoje inimagináveis.

\subsection{Audições Musicais}

Estas têm sido os eventos mais comuns. Não há dúvida que a seleção do repertório importa muito, porém o que se deve evitar são os radicalismos: um museu de arte sacra não deve, por isso, permitir apenas concertos de música sacra. Porém, a atmosfera do lugar deve ser levada em conta. Ter um conjunto tocando heavy-metal numa igreja barroca não é apenas estranho, mas uma provocação aos sentimentos religiosos de quantos freqüentem o templo.

O horário, que enı um primeiro momento parece ser tão óbvio, representa, na verdade, uma questão delicada. Muitos eventos de audições musicais fracassaram pela cscolha errada do horário. Há alguns anos, em um prédio histórico no centro de São Paulo, decidiu-se por audições aos domingos às nove horas da manhã. O resultado foi desastroso. Respeitar os hábitos do público-alvo é essencial, mas a experiência tem demonstrado alguns poucos parâmetros. Um concerto antes do museu abrir todas as suas dependências - incluindo biblioteca, loja de souvenirs, livraria, lanchonetc restaurante ou similar - costuma ter como resultado a evasão do público logo após o seu término. Com isso, perde-se uma boa oportunidade de atrair estc espectador para os outros atrativos do museu. Tem-se revelado um bom horário - alguns museus vêm fazendo isso com sucesso - a última hora antes 
de encerrar-se a visitação. O público que chegar com alguma antecedência pode manifestar interesse pelo acervo c, mesmo que não dê tempo de percorrer todas suas salas c corredores, sentir-se-á motivado a voltar com mais calma

\subsection{Teatro}

Pode ocorrer que o museu disponha de um auditório com palco suficientemente adequado para representações teatrais, cuja temática tenha ou não ligação com o propósito do acervo ou da exposição temporária. Dc qualquer modo, as recomendações para as audições musicais são, em certa medida, também válidas para o teatro.

Em muitas casas históricas e muscus não há sequer auditório. Isso, em princípio, não inviabiliza o teatro. Um cômodo ou um conjunto deles pode ser preparado para isso. Neste caso, não apenas as paredes c o piso antigos, mas a mobília rcsistente formam o cenário espetacular para a representação. Excmplo bem-sucedidodesta proposta está na encenação da peça "Tamara", no casarão Porto Seguro, cm São Paulo. Embora não seja um museu, a casa antiga de um bairro de elite, decorada com artefatos de requinte, é o cenário para a peça, onde o público acompanha os atores pelos diversos cômodos no desenrolar da trama.

Achar que $\mathrm{cm}$ um museu, com peças cxpostas $\mathrm{cm}$ redomas, torna-se inviável uma apresentação deste tipo é, no íntimo, ceder ao pavor das novas propostas. A encenação dosúltimos momentos do presidente Getúlio Vargas, no Museu da República do Rio de Janciro, prova a possiblidade deste tipo de evento.(SOUZA, 1991)

\subsection{Espetáculo de Multimídia}

Tal conceito é hoje quase que sinônimo de alta tecnologia, embora possa ser realizado com recursos de modesta tecnologia (o que não significa necessariamente baixo custo). Digno de nota foi o projeto para o espetáculo de "Som e Luz", inicialmente claborado como parte das comemorações do sesquicentenário da Independência, em 1972.

Através de um sistema de luzes c caixas acústicas distribuidos estrategicamentc pelos jardins do Parque da Independência, o grande edifício do Museu Paulista do Ipiranga c o bosque recebiam vários tipos de iluminação, ao mesmo tempo em que um elenco de conhecidos atores narrava, através de uma gravação, a história do Brasil por meio de seus persongens mais conhecidos, como Anchieta, Fernão Dias Paes Leme, d. Pedro I, princesa Isabel. Ideologicamente tendencioso ou não, o espetáculo muito bem mon- tado atraía verdadeiras multidões ao parque. Infelizmente, em poucos anos, o aparato tecnológico deteriorou-se quase que completamente.

Na linha da alta tecnologia, encontra-se a mostra da Casa Vermelha, em Curitiba, no evento "Curitiba Tempo e Caminhos". Através de computadores c iluminação o visitante percorre a exposição obtendo informações sobre a história da cidade, inserido em uma espécic de cenário de objetos representativos (EDUARDO, 1993). A idéiade museu como local que mostra a obsolescência de artefatos de uma mancira pouco ou nada atraente ganha, desta maneira, uma dimensão que procura e consegue fugir das amostras cnfadonhas onde, não raro, visitantes comuns c até certos especialistas boccjam.

\section{CONSIDERAÇÕES FINAIS}

Salas fechadas, dependências mal-iluminadas, acervos $\mathrm{cm}$ processo aceleradodedeterioração, osmuseuse localidades históricasencontram-se subutilizados, alguns quase que desertos. A parceria empresa-cultura não ć um modismo a mais; talvez seja uma das poucas saidas, protestem ou não os "puristas".

Posto este quadro, torna-se quase pueril falar em turismo cultural, pois nestas localidades falta praticamente tudo ao visitante

Raras são as vezes que em encontros sobre patrimônio histórico ou muscus ć abordada a questão da visitação turística. Exposições temporárias são importantes, porém, sem nenhum apreço ao turista, obras famosas são recolhidas, frustrando expectativas de quem planejou uma viagem com antecedência desejando conhecer in loco originais famosos. E isso ocorre muito mais por ausência de estratégia de marketing do que por dificuldades resultantes da falta de cspaço em museus.

Mão-de-obra cspecializada e, principalmente, a consciência deque não apenas em marketing, mas cm turismo, não há a "sabedoria total". O profissional de turismo terá que saber lidar com muitas informações de diversas ciências sem, contudo, ser especialista em nenhuma delas, necessitando, portanto, de auxílio de especialistas das áreas afins.

Os turistas voltarão a visitar as localidades históricas assim que estas oferecerem condições para tanto, o que não está ocorrendo, e também quando os setores envolvidos na administração de museus e casas históricas enxergarem estes locais não apenas como templos sagrados do saber, refúgio inexpugnável ao mundo farisaico das empresas ou palco de onde o turista deve manter-se distante. Quer algumas autoridades queiram quer não, "seus" museus se integram no quadro dos recursos turísticos das suas cidades e a má vontade com o visitante de fora, ao contrário de preservar uma suposta "pureza" de princípios pedagógicos, contribuirá a passos largos 
para a bancarrota e o definitivo fechamento de suas portas. A realidade dos anos 90 mostrará isso.

\section{REFERÊNCIAS BIBLIOGRÁFICAS}

EDUARDO, Jorge. 1993. Mostra usa tecnologia e arte para contar Curitiba. O Estado de São Paulo, 4 maio, p. 6.

MUYLAERT, Roberto. 1993. Marketing cultural \& comunicação dirigida. São Paulo: Globo. PHILLIPS, William E. et alii. 1992. Arte-empresa: uma parceria multiplicadora. São Paulo: TichetGrupo de Serviços.

SHAEFFER, Enrico. 1963. Os museus europeus. Um ensaio. Revista de História. São Paulo, n. 53. SOUZA, Okky. 1991. De volta ao Catete. Veja, 23 out., p. 116-7. 